\title{
Reality or singular pipe dream?
}

\author{
Ronald K. Woods, MD, PhD
}

\footnotetext{
From the Division of Cardiothoracic Surgery, Department of Surgery, Medical College of Wisconsin, and Herma Heart Center, Children's Hospital of Wisconsin, Milwaukee, Wis.

Disclosures: Author has nothing to disclose with regard to commercial support.

Received for publication Aug 22, 2016; accepted for publication Aug 26, 2016; available ahead of print Sept 28, 2016.

Address for reprints: Ronald K. Woods, MD, PhD, Division of Cardiothoracic Surgery, Department of Surgery, Medical College of Wisconsin, Children's Hospital of Wisconsin, 9000 W Wisconsin Ave, MS B 730, Milwaukee, WI 53226 (E-mail: rwoods@ @ chw.org).

J Thorac Cardiovasc Surg 2017;153:183

$0022-5223 / \$ 36.00$

Copyright (c) 2016 by The American Association for Thoracic Surgery

http://dx.doi.org/10.1016/j.jtcvs.2016.08.054
}

Zhou and colleagues, ${ }^{1}$ in a prototype proof-of-concept study, have introduced a transapical dual-lumen cannula with inflow below and outflow above the aortic valve for the purpose of providing a "better" option of neonatal left ventricular assist device support. ${ }^{1}$ By using 6 neonatal lambs and a paracorporeal centrifugal pump, they demonstrated good support and no complications. Duration of support was 6 hours. I am respectful of this group and their work, and I thank them for their present effort focused on neonates.

In part, this concept has been demonstrated with devices currently being used for adults, the latter albeit without the transapical approach. ${ }^{2-4}$ Assuming the approach works well, one can debate the merits of a single-cannula paracorporeal system versus other neonatal support options (eg, extracorporeal membrane oxygenation, other dual cannulation, paracorporeal nonextracorporeal membrane oxygenation strategies). I will not focus on the many viewpoints that may exist on this issue.

My primary concern with this cannula is the transition from the latitude afforded by a proof-of-concept context to its actual application and validity in a human neonate. The body of the cannula housing the inflow is $6 \mathrm{~mm}$ (cross-sectional area of $28.3 \mathrm{~mm}^{2}$ ), and the diameter of the infusion cannula is $4.3 \mathrm{~mm}$ (area of $14.5 \mathrm{~mm}^{2}$ ). The aortic annular diameter of the neonatal lambs in this study was approximately $14 \mathrm{~mm}$, which also approximates the distance in diastole between the anterior mitral leaflet and the outflow septum (wherein the inflow portion of cannula resides). The corresponding figure for a typical $3.5-\mathrm{kg}$ human neonate is approximately $7 \mathrm{~mm}$. This translates to a 4-fold increase in the fractional cross-sectional area occupied by the pump within the outflow tract, valve, or aorta: $18 \%$ for the lamb and $73 \%$ for a human neonate. No doubt, the authors recognize the risk this poses of (1) inadequate drainage because of size constraints; (2) injury to the mitral valve or subvalve apparatus; or (3) injury to the aortic valve or aortic insufficiency. Can the catheter be downsized 4-fold or to a degree to allow it to function safely and effectively? support? work progresses.

\section{References}

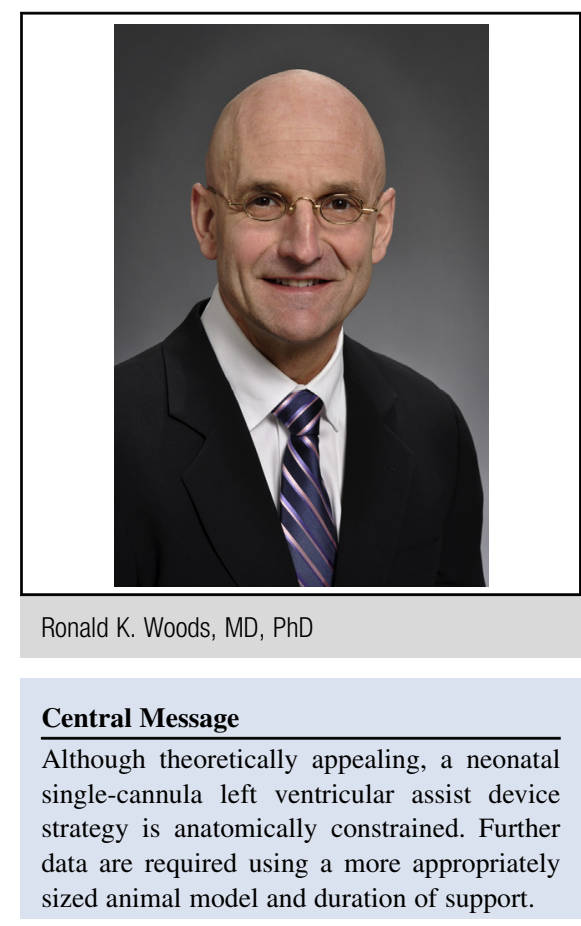

See Article page 175 .

If so, how will the catheter perform over a longer duration of

Another potential issue, particularly given the laxity of neonatal soft tissue, is the lever-arm effect. Compared with standard left ventricular assist device apical inflow cannulas, the dual-lumen cannula has more length inside the heart/aorta. Therefore, any motion of the externalized portion will translate to greater motion at the distal (aortic) end of the cannula. This could affect both inflow and outflow performance and the mitral and aortic valves. I trust Zhou and colleagues ${ }^{1}$ will consider these issues as their

1. Zhou C, Wang D, Ballard-Croft C, Zhao G, Reda HK, Topaz S, et al. A transapical to aorta double lumen cannula-based neonate LVAD efficiently unloads the LV in neonate lambs. J Thorac Cardiovasc Surg. 2017;153:175-82.

2. Burzotta F, Trani C, Doshi SN, Townend J, van Geuns RJ, Hunziker P, et al. Impella ventricular support in clinical practice: collaborative viewpoint from a European expert user group. Int J Cardiol. 2015;201:684-91.

3. Spratt JR, Raveendran G, Liao K, John R. Novel percutaneous mechanical circulatory support devices and their expanding applications. Expert Rev Cardiovasc Therapy. 2016;14:1133-50.

4. Kazui T, Tran PL, Echeverria A, Jerman CF, Iwanski J, Kim SS, et al. Minimally invasive approach for percutaneous CentriMag right ventricular assist device support using a single PROTEKDuo cannula. J Cardiothorac Surg. 2016;11:123. 